\title{
Suatu Kajian Literatur Masalah- Masalah yang Dihadapi dalam Mata Kuliah Jaringan Komputer
}

\author{
Mahesi Agni Zaus ${ }^{1 *}$, Krismadinata ${ }^{2}$ \\ ${ }^{1}$ Pendidikan Teknologi dan Kejuruan, Fakultas Teknik, Universitas Negeri Padang \\ ${ }^{2}$ Jurusan Teknik Elektro, Fakultas Teknik, Universitas Negeri Padang \\ *Corresponding author, e-mail: mahesiagnizaus@gmail.com
}

\begin{abstract}
Abstrak - Matakuliah jaringan computer adalah yang merupakan mata kuliah dasar yang harus dikuasai oleh mahasiswa jurusan Teknik Informatika. Pembelajaran yang praktis dan menarik memiliki peran yang menarik dalam proses pembelajaran. Pembelajaran yang menarik dapat meningkatkan hasil belajar siswa serta membantu siswa dalam meningkatkan pemahaman mereka, serta meningkatkan motivasi mereka dalam meningkatkan hasil belajar serta pengetahuan mereka. Artikel ini akan membahas masalah-masalah yang berhubungan dengan mata kuliah jaringan computer yang bersifat metode pengajaran serta media pembelajaran. Berdasarkan tujuan mata kuliah jaringan computer maka diusulkan untuk mengoptimalkan konten dalam pengajaran serta pada media pembelajaran diusulkan mengadopsi software simulasi agar pengajaran menjadi menarik.
\end{abstract}

\section{Kata Kunci : Jaringan Komputer, Simulasi, Metode Pengajaran, Media Pembelajaran}

\begin{abstract}
Computer network course is a subject that is the basic course that must be mastered by students majoring in Informatics Engineering. Practical and interesting learning has an interesting role in the learning process. Exciting learning can improve student learning outcomes and help students improve their understanding, as well as increase their motivation to improve their learning outcomes and knowledge. This article will discuss the problems related to computer network courses that are teaching methods and learning media. Based on the objectives of computer network courses it is proposed to optimize the content in teaching as well as on instructional media proposed to adopt software simulation for teaching to be interesting.
\end{abstract}

Keywords : Computer Networking, Simulation, Teaching Method, Instructional Media

This is an open access article distributed under the Creative Commons 4.0 Attribution License, which permits unrestricted use, distribution, and reproduction in any medium, provided the original work is properly cited. C2018 by Author and Universitas Negeri Padang

\section{Pendahuluan}

Penggunaan luas Internet, khususnya World Wide Web (web) telah membuat pengajaran jaringan komputer merupakan keharusan bagi banyak universitas dan perguruan tinggi. Siswa mengambil jaringan kursus terkait berharap mendapatkan pengetahuan langsung tentang cara kerja internet, cara web berfungsi, cara mengatur jaringan operasional dan bagaimana memprogram jaringan untuk menyampaikan beragam aplikasi.

Secara umum, tiga pendekatan digunakan untuk mencakup topik utama: bottom-up, yang dimulai pada lapisan terendah (fisik) dari protokol dan bekerja dengan cara naik; top-down, yang dimulai dari yang lebih tinggi

lapisan seperti aplikasi; dan campuran keduanya. Meskipun sebagian besar program melibatkan beberapa proyek, beberapa di antara mereka sebenarnya telah mendedikasikan setiap minggu latihan laboratorium.

Isi proyek dan latihan laboratorium bervariasi, dan termasuk: melihat desain dan implementasi protokol, pemrograman prosesor jaringan yang sebenarnya, menulis perangkat lunak klien-server dalam berbagai bahasa pemrograman, pengaturan jaringan operasional perangkat keras dan perangkat lunak, dan bereksperimen dengan protokol menggunakan perangkat lunak simulasi jaringan. 
Jaringan komputer adalah kursus penting di banyak sekolah teknik, apakah itu ditawarkan dalam ilmu komputer, teknik elektro, atau ilmu informasi. Tujuan yang dinyatakan bervariasi dari kursus ke kursus. Beberapa elemen umum dari tujuan kursus dapat diringkas sebagai berikut:

a. Siswa menguasai konsep dasar jaringan komputer modern

b. Siswa belajar bagaimana mengembangkan aplikasi jaringan menggunakan bahasa pemrograman

c. Siswa memahami arsitektur umum jaringan komputer dan bagaimana berlapis protokol jaringan komputer bekerja

d. Siswa dapat mengidentifikasi dan menjelaskan topik saat ini di jaringan komputer, seperti keamanan dan kualitas layanan

Perkembangan jaringan komputer sangatlah cepat, serta perkembangan software pun terus meningkat, software yang berkembang sudah menuju arah jaringan komputer atau terhubung dengan internet of thing [1][2].

Dengan perkembangan jaringan komputer yang cepat, pengembangan perangkat lunak juga mulai berkembang menuju arah jaringan. Jadi, untuk mahasiswa khusus rekayasa perangkat lunak, mereka harus memperoleh pengetahuan tertentu dari jaringan komputer. Ini merupakan dasar penting bagi mereka untuk terlibat dalam profesional bekerja lebih baik di masa depan. Namun, perkembangan teknologi jaringan yang cepat terus terjadi meneruskan persyaratan baru untuk pengajaran kursus jaringan komputer universitas. Peningkatan versi protokol jaringan terus-menerus, munculnya teknologi baru, dan meningkatnya poin pengetahuan baru membuat siswa belajar dan guru mengajar lebih banyak dan lebih sulit. jaringan komputer adalah matakuliah dasar profesional untuk mahasiswa komputer. Itu sangat teoritis dan praktis.

Ajaran jaringan komputer seharusnya tidak hanya fokus pada teori jaringan, arsitektur jaringan dan analisis protokol, tetapi juga penekanan pada kemampuan siswa untuk mengatur jaringan, mengelola dan memelihara jaringan, dan mengembangkan aplikasi berdasarkan penguasaan prinsip dan konsep dasar. Selain itu, untuk banyak teori kursus ini, siswa perlu bereksperimen dan berlatih untuk lebih memahami dan memahami. Sebagai suplemen penting untuk pengajaran teori, pengajaran praktis adalah cara efektif untuk internalisasi pengetahuan. Ini membantu siswa untuk secara bertahap memperdalam pemahaman pengetahuan teoritis, mengoptimalkan struktur pengetahuan siswa secara bertahap, sehingga mereka dapat menerapkan pengetahuan mereka untuk kegiatan kreatif.

Oleh karena itu, perlu dilakukan penelitian tentang pengajaran praktis jaringan komputer untuk membantu siswa lebih memahami dan menguasai pengetahuan tentang jaringan komputer dan mengembangkan kapasitas inovatif mereka.

Jadi untuk mahasiswa Teknik Informatika mereka harus mendapat pengetahuan dari jaringan komputer, ini merupakan dasar bagi mereka untuk menghadapi dunia kerja setelah lulus nanti [3][4].

Jaringan komputer dari waktu kewaktu pun makin berubah, teknologi-teknologi baru pun tercipta, sehingga pengetahuan baru harus diikuti oleh universitas agar dapat menciptakan lulusan yang mempunyai pengetahuan yang dibutuhkan oleh dunia kerja.[4][5]. Peningkatan versi protocol jaringan meningkatkan pengetahuan baru sehingga Dosen harus mempu mengajarkan lebih banyak dan lebih sulit. Metode pengajaran tidak hanya teori namun juga mencakup praktek jaringan computer [6].

Mahasiswa dituntut mampu menguasai konsep teori jaringan komputer dan mampu berlatih membuat, mengatur dan mengelola jaringan komputer [5]. Sebagai suplemen penting dalam pengajaran jaringan komputer pengajaran yang menarik adalah cara efektif yang dapat membantu siswa dalam memahami teori serta dapat menerapkan pengetahuan yang didapat kedalam praktek jaringan komputer [7][8]. Oleh karena itu perlu dilakukan penelitian tentang metode pengajaran yang menarik untuk membantu siswa untuk dapat memahami dan menguasai pengetahuan tentang jaringan komputer.

\section{Studi Pustaka}

Tujuan dari praktek matakuliah jaringan komputer adalah untuk mengembangkan kemampuan jaringan mahasiswa dalam mendesain, mengaplikasikan, mengatur dan mengelola jaringan komputer. [9]Dalam matakuliah jaringan komputer ada beberapa masalah yang ditemukan pada banyak universitas:

i. Metode Pengajaran pada matakuliah Jaringan Komputer tidak sesuai lagi dengan tuntunan zaman sekarang [10][11].

Saat ini pengajaran jaringan komputer hanya berupa teori dikelas [12] sehingga mahasiswa tidak dapat mengaplikasikan 
teori yang sudah didapat kedalam keadaan yang nyata. Dalam penguasaaan teori mahasiswa bisa saja mendapatkan nilai yang tinggi tetapi untuk pengaplikasian belum tentu bisa.

Saat ini, pengajaran eksperimental jaringan komputer terutama dilakukan di sekitar teori pengajaran kelas, proyek-proyek eksperimental ditetapkan untuk membantu siswa memahami isi dari pengajaran di kelas. Karena kurangnya pengetahuan eksperimental jaringan komputer, orang berpikir percobaan jaringan komputer terutama adalah eksperimen konfirmasi untuk waktu yang lama. Eksperimen mengajar tanggungan pada pengajaran teori, isi dari eksperimen tidak sistematis dan sangat sewenang-wenang, dan bentuknya juga longgar. Sehingga, banyak siswa yang tidak mampu menghubungkan teori dan praktik.

Beberapa siswa mendapat nilai tinggi setelah menyelesaikan kursus, tetapi mereka tidak dapat memahami secara mendalam pengetahuan teori jaringan komputer, terutama mereka tidak dapat menerapkan pengetahuan mereka untuk praktis aplikasi, apalagi pengembangan kemampuan inovatif. Ini menunjukkan bahwa eksperimen tradisional konten belum dapat memenuhi persyaratan baru dari era baru di era advokasi kualitas pendidikan dan menekankan pengembangan kapasitas.

ii. Sarana untuk Praktek Jaringan Komputer sangat minim.[13][14][15][16]

Praktek Jaringan komputer tentu saja menuntut adanya sarana dalam melakukan praktek. Seperti PC, HUB, Switch, dll. Siswa perlu melakukan praktek hardware maupun software serta perangkat yang relevan dengan teknologi yang berkembang saat ini. Di Universitas yang bagus mahasiswa diajarkan pada laboratorium yang besar dengan peralatan yang relevan dengan teknologi saat ini. Biaya pengadaan perangkat keras serta pemeliharaanya sangat tinggi. Di beberpa Unversitas tidak mampu membangun laboratorium dan menyediakan hardware dan software yang relevan karena kurangnya dana pengadaan sehingga ada beberapa praktek yang tidak dapat dilakukan pada praktek jaringan komputer.[17][18] [13][19][20]. Sehingga kemampuan siswa hanya berbatas pada teori yang didapat dari dosen.

Siswa perlu melakukan eksperimen perangkat lunak dan eksperimen perangkat keras. Tidak hanya beberapa yang terpisah komputer tetapi juga peralatan dan peralatan jaringan yang relevan diperlukan. Akibatnya, para siswa tidak dapat menghubungkan teori dengan praktik dan menerapkan pengetahuan mereka untuk memecahkan masalah praktis. Selain itu, ini jenis skema percobaan sepenuhnya tergantung pada perangkat keras memiliki beberapa kerugian, misalnya, ukuran eksperimental terbatas,. Jadi, kita harus menemukan skema eksperimen yang efektif dan mudah dikelola untuk disediakan siswa dengan lebih banyak kesempatan untuk bereksperimen dan berlatih.

iii. Metode Pengajaran Praktek Komputer hanya Monoton, yang tidak memotivasi siswa dalam belajar.

Praktek Jaringan komputer berfungsi untuk melatih kemampuan siswa agar mempu mengaplikasikan teori yang sudag diajarkan oleh dosen kedalam praktek nyata. Namun sebagian besar metode pengajaran praktek jaringan komputer sudah ditetapkan sesuai dengan langkah-langkah tertentu dan caracara tertentu untuk memperoleh hasil tertentu. Siswa tidak dapat berpikir secara mandiri, mereka hanya mengikuti langkahlangkah yang sudah ada sehingga mengakibatkan motivasi siswa jadi melemah [21]. Siswa tidak dapat bertanya mengapa, kenapa, bagaimana sehingga inovasi dan kreatifitas mereka dibatasi [22].

Oleh karena itu dibutuhkan inovasi dalam metode pengajaran praktek yang dapat meningkatkan motivasi siswa dalam belajar. Dengan demikian, bagaimana supaya metode pengajaran meningtegrasikan dalm mengoptimalkan praktek jaringan komputer, merancang jaringan yang cocok untuk mahasiswa [23][24][25][26][27].

Dengan demikian, bagaimana mengintegrasi-kan dan mengoptimalkan konten percobaan dan merancang proyek percobaan cocok untuk siswa tingkat yang berbeda, bagaimana menggunakan sumber daya yang terbatas untuk membangun yang ilmiah dan masuk akal platform pengajaran eksperimen, dan bagaimana memotivasi minat siswa sebanyak mungkin, dll., ini adalah masalah yang harus dipecahkan. Akibatnya, perlu untuk 
mereformasi ajaran praktis saat ini modus jaringan komputer dan menjelajahi mode mengajar praktis memenuhi kebutuhan sosial

pengembangan, sehingga meletakkan dasar yang kuat untuk pelatihan bakat perangkat lunak dengan kualitas teknik dan kemampuan inovasi.

\section{METODE}

Penelitian ini menggunakan metode studi literatur dengan mereview sebanyak 100 jurnal yang berkaitan dengan matakuliah jaringan komputer. Jurnal yang direview 15 tahun terakhir.

Adapun tinjauan sistematis yang dilakukan berdasarkan data literatur penelitian sebelumnya, dilakukan berdasarkan langkah berikut, Pertama, jumlah total studi awal yang kami temukan dari edatabase adalah 100. Kedua, dilakukan penyaringan jurnal yang terkait dengan masalah yang dihadapi pada mata kuliah jaringan komputer sebanyak 43 jurnal.

\section{Hasil dan Pembahasan}

Untuk mencapai tujuan dari jaringan komputer maka perlu adanya meoptimalan dari beberapa sisi pengajaran praktek jaringan komputer sebagai berikut :

1) Mengoptimalkan Metode pengajaran jaringan komputer sesuai dengan perkembangan zaman

Hal pertama dosen harus mengoerientasikan tujuan dan mata kuliah jaringan komputer, mengoptimalkan dan mengintegrasikan praktek dan menambahkan praktek yang sudah sirancang menjadi praktek yang komprehensif. Serta proyek harus diklasifikasikan dan diberi peringkat sehingga mahasiswa dapat belajar berdasarkan karakteritistik serta pembelajaran secara mandiri. Berikut beberapa contoh proyek yang berbeda level jaringan

Tabel 1 Proyek Pratikum Jaringan

\begin{tabular}{|l|l|l|}
\hline No & Layer Jaringan & Praktek Jaringan \\
\hline 1 & $\begin{array}{l}\text { Applicattion } \\
\text { Layer }\end{array}$ & $\begin{array}{l}\text { Protocol analisis HTTPS } \\
\text { dan DNS }\end{array}$ \\
\cline { 3 - 3 } & & $\begin{array}{l}\text { Konfigurasi dan } \\
\text { Manajemen Server DNS }\end{array}$ \\
\cline { 3 - 3 } & & Programming Socket \\
\hline 2 & $\begin{array}{l}\text { Transport } \\
\text { Layer }\end{array}$ & $\begin{array}{l}\text { Analisis protocol IP } \\
\text { Konfigurasi statis dan } \\
\text { dinamis routing }\end{array}$ \\
\hline 3 & Network Layer & Analisis protocol IP \\
\hline
\end{tabular}

\begin{tabular}{|c|c|c|}
\hline & & $\begin{array}{l}\text { Konfigurasi statis dan } \\
\text { dinamis roouting }\end{array}$ \\
\hline & & $\begin{array}{l}\text { Menggunakan ICMP } \\
\text { protocol pada ping dan } \\
\text { tracert command }\end{array}$ \\
\hline 4 & Data Link layer & Analisis protocol ARP \\
\hline 5 & Physical later & $\begin{array}{l}\text { Membuat jaringan kabe } \\
\text { dan jaringan }\end{array}$ \\
\hline
\end{tabular}

Dari tabel di atas, kita dapat melihat ada tiga jenis eksperimen di lapisan aplikasi, yang adalah konfigurasi dan pengelolaan server jaringan, analisis protokol, dan pemrograman Scoket. Di lapisan transport dua percobaan analisis protokol ditetapkan. Di lapisan jaringan konfigurasi routing mengatur di samping dua percobaan analisis protokol. Pada lapisan tautan data, eksperimen analisis protokol sudah diatur. Dalam lapisan fisik percobaan pembuatan kabel jaringan dan jaringan sudah diatur. Semua percobaan dari kursus ini dapat dibagi menjadi empat jenis, dari yang sulit hingga yang mudah seperti berikut: pemrograman percobaan, percobaan analisis protokol, konfigurasi jaringan dan percobaan manajemen, dan percobaan jaringan. Di antara mereka, percobaan pemrograman relatif lebih sulit untuk siswa baru untuk pemrograman tingkat tinggi, yang mungkin opsional berdasarkan silabus dan jam kelas. Untuk eksperimen lain, siswa diminta untuk menyelesaikannya secara prinsip. Tetapi guru mungkin membutuhkan persyaratan yang berbeda dari siswa yang berbeda.

2) Mengadopsi software simulasi jaringan komputer

Untuk mengatasi kekurangan sarana untuk praktek jaringan komputer maka dosen dapat merancang pengajaran praktek jaringan komputer menggunakan software simulasi dalam konsisi laboratorium yang ada. Serta menggabungkan pengajaran lain untuk membangun praktek jaringan baru, jadi mahasiswa dapat dengan mudah praktek jaringan komputer dan berpartisipasi aktif dan kooperatif dalam membangun jaringan.

Dari beberapa tahun terakhir perusahaan sudah banyak mengembangkan beberapa software simulasi jaringan komputer yang menyediakan platform untuk praktek jaringan komputer. Sebagai contoh Packet Tracer, Net Sim, V Net dll [28][29][30]. Simulasi yang ditawarkan dapat menghemat biaya peralatan tetapi juga memfasilitasi mahasiswa untuk belajar secara mandiri dan dapat praktek berulang-ulang setelah 
berada diluar kelas. Sehingga cara ini efektif dapat mmecahkan masalah utama dalam pengadaan laboratorium jaringan komputer.

Pengajaran eksperimental berdasarkan perangkat lunak simulasi jaringan adalah solusi yang lebih baik untuk jaringan komputer Tentu saja, yang memiliki banyak kelebihan, misalnya, jarang dibatasi oleh sumber daya perangkat keras dan bisa digunakan bekerjasama dengan peralatan laboratorium lainnya; skala eksperimental mudah diperluas, mudah untuk kelola dan tingkatkan serta gabungkan dengan perangkat keras dan perangkat lunak lainnya secara bersama untuk membentuk yang lengkap sistem pengajaran eksperimental jaringan. Karena lebih dari satu komputer biasanya dibutuhkan dalam jaringan percobaan, kita dapat mengoordinasikan perangkat lunak Mesin Virtual dengan alat lain bersama-sama untuk menyelesaikan percobaan. Misalnya, untuk beberapa eksperimen komprehensif yang lebih kompleks, mesin virtual (seperti VPC) dapat digunakan untuk bekerja sama dengan Dynamsips untuk menyelesaikannya; untuk konfigurasi layanan sederhana, mesin virtual dengan server windows 2003 dapat digunakan untuk menyelesaikan konfigurasi; untuk percobaan analisis protokol, kami dapat menggunakan Ethereal (perangkat lunak analisis protokol) dan virtual mesin untuk menyelesaikan. Skema percobaan ini tidak hanya dapat menghemat banyak peralatan, tetapi juga memfasilitasi siswa untuk berulang kali berlatih setelah kelas. Akibatnya, secara efektif dapat memecahkan masalah utama konstruksi laboratorium jaringan saat ini dan meningkatkan kualitas pengajaran jaringan.

3) Menerapkan Metode Pengajaran yang berpusat pada siswa.[31][32][33]

Metode pengajaran yang berpusat pada mahasiswa akan mempengaruhi sikap siswa dalam belajar seperti kemampuan, inovasi serta kesadaran diri sendiri. Beberapa universitas sudah menerapkan metode pengajaran berpusat pada siswa seperti Project Based Learning [34], Problem Based Learning, Cooperatif Learning, Blendeed Learning dan banyak lagi contohnya,[35] [36] penggunaan pendekatan pembelajaran ini juga tergantung dengan keadaan yang spesifik dan disesuaikan dengan analisis kebutuhan [37].

Saat ini metode pengajaran yang diterapkan mengatur pengajaran yang menarik bagi mahasiswa, mahasiswa mampu memecahkan masalah, menjawab pertanyaan melalui praktek yang dilakukan. Metode pengajaran yang tepat tidak hanya meningkatkan motivasi mahasiswa dalam belajar meningkatkan keahlian mahasiswa, menganalisis dan memecahkan maslah tetapi juga menumbuhkan semangat inovasi dan kerja sama [38][30][39].

Dalam penerapan metode pengajaran tentu saja efeknya berbeda pada masing-masing mahasiswa, karen itu perlu diperlajari lebih lanjut metode pengajaran yang disesuaikan dengan karakteristik mahasiswa yang berbeda [40][41].

Metode pengajaran utama termasuk pendekatan berbasis tugas, pengelompokan eksperimen pendekatan, pendekatan pengajaran jaringan, pendekatan pengajaran kasus, dan sebagainya. Dalam pengajaran praktis yang sebenarnya, metode ini dapat terjalin untuk digunakan tergantung pada keadaan spesifik. Bagaimana mengatur ini metode pengajaran secara ilmiah dan efektif secara langsung akan mempengaruhi efektivitas eksperimental pengajaran.

a. Pendekatan pengajaran partisipasi, juga dikenal sebagai pendekatan berbasis tugas. Guru pertama mengatur beberapa tema atau masalah sesuai dengan tujuan pengajaran dan isi pengajaran, mengatur siswa untuk diskusikan mereka untuk menemukan caracara menyelesaikan tugas-tugas; kemudian para siswa menerapkan pengetahuan mereka bereksperimen, setelah itu memperkenalkan solusi mereka ke masalah percobaan di kelas; akhirnya guru ulas dan jelaskan hasil eksperimen yang diperoleh siswa. Pendekatan pengajaran ini memungkinkan siswa untuk berpartisipasi penuh dalam proses pengajaran, sehingga sangat meningkatkan antusiasme siswa untuk berpartisipasi dalam pengajaran praktis.

b. Mengelompokkan pendekatan eksperimen. Untuk beberapa percobaan, terutama yang terkait dengan berbagai macamperalatan laboratorium dan operasi berulang yang membosankan, pendekatan ini dapat digunakan. Guru mengatur topik percobaan, siswa membentuk kelompok mereka sendiri secara bebas, dan setiap kelompok memilih seorang pemimpin, siapa bertanggung jawab untuk penelitian tim. Pendekatan ini, di satu sisi, memecahkan masalah kekurangan peralatan jaringan. Di sisi lain, itu juga memupuk semangat tim siswa dan 
meningkatkan kemampuan beradaptasi untuk bekerja di masa depan.

c. Pendekatan pengajaran jaringan. Guru mengatur siswa untuk mengacu pada teknologi, metode yang terkait dan aplikasi produk jaringan, aplikasi jaringan, perangkat lunak manajemen jaringan dan alat pengembangan jaringan di Internet untuk menemukan solusi untuk masalah eksperimental. Ini Pendekatan pengajaran dapat mengembangkan kebiasaan belajar mandiri siswa yang baik dan meningkatkan mereka kemampuan menerapkan pengetahuan untuk memecahkan masalah praktis secara mandiri.

d. Pendekatan pengajaran kasus. Teknologi jaringan sangat praktis dan setiap proyek jaringan adalah baik kasus mengajar. Guru menunjukkan dan menjelaskan kasus percobaan operasional spesifik, dan memungkinkan siswa untuk menguasai metode operasi dan metode desain melalui casing analisis dan demonstrasi. Pendekatan ini dapat meningkatkan persepsi siswa yang terkait dengan operasi dan metode dan meningkatkan efektivitas pengajaran.

Saat ini, metode yang digerakkan oleh masalah terutama diadopsi untuk mengatur pengajaran praktis komputer kursus jaringan, yaitu, untuk memungkinkan siswa memecahkan masalah dan menjawab pertanyaan melalui eksperimen. Selain itu, metode pengelompokan eksperimen dan diskusi juga diadopsi dalam beberapa eksperimen.

Untuk pengetahuan yang terkait dengan konten percobaan, saya mengadopsi pendekatan pengajaran jaringan, memungkinkan siswa temukan jawabannya melalui mencari informasi di Internet, seperti fungsi dan penggunaan Ethereal dan TTCP. Selama percobaan, kita harus sepenuhnya mencerminkan bahwa siswa adalah peserta utamanya, sehingga siswa dapat memperoleh pengalaman sukses dari kemampuan dan emosi melalui partisipasi aktif dan penelitian kooperatif, sehingga membangun kepercayaan diri mereka dan mengalami kesenangan eksplorasi dan penciptaan.

Aplikasi komprehensif dari metode pengajaran ini tidak hanya sangat merangsang antusiasme siswa, meningkatkan kemampuan tangan mereka, dan melatih kemampuan siswa dalam menganalisis dan memecahkan masalah, tetapi juga menumbuhkan semangat inovasi dan kerja sama mereka. Tentu saja, karena perbedaan masing-masing siswa, metode ini memiliki efek yang berbeda pada siswa yang berbeda. Karena itu, kita juga perlu jelajahi metode pengajaran eksperimental yang disesuaikan dengan siswa dengan karakteristik yang berbeda, sepenuhnya merangsang minat belajar siswa, membantu sebanyak mungkin siswa untuk memahami pengetahuan kelas mendalam, dan mengembangkan kualitas teknik dan kemampuan inovasi mereka.

\section{KeSIMPUlan}

Dari hasil penelitian dan pembahasan didapat bahwa metode pengajaran yang menarik dan sesuai dengan perkembangan zaman dalam praktek jaringan komputer adalah salah satu cara untuk mencapai tujuan mata kuliah jaringan komputer.

Metode pengajaran memiliki peranan penting dalam meningkatkan hasil belajar serta meningkatkan motivasi siswa dalam belajar. Dengan perkembangan teknologi jaringan komputer yang pesat maka dibutuhkan inovasi dalam pengajaran jaringan komputer. Dosen harus mampu mengadopsi ide-ide baru dan terus belajar untuk mengikuti perkembangan zaman sehingga tercapainya tujuan pembelajaran [42][43].

Ajaran praktis dari kursus jaringan komputer adalah cara yang diperlukan untuk mencapai tujuan pengajaran. Ini memainkan peran khusus dalam meningkatkan kualitas siswa yang komprehensif, melatih semangat kreatif siswa dan meningkatkan kemampuan praktis siswa. Dengan perkembangan jaringan komputer yang pesat teknologi, reformasi pengajaran eksperimental jaringan komputer akan memiliki jalan panjang untuk pergi. Kita harus mengadopsi ide-ide baru dan terus belajar dan mengeksplorasi untuk mengikuti laju perkembangan waktu dan untuk melatih talenta komputer yang lebih praktis dan inovatif bagi masyarakat.[44]

\section{DAftar Pustaka}

[1] F. Shrouf, J. Ordieres, And G. Miragliotta, "Smart Factories In Industry 4.0: A Review Of The Concept And Of Energy Management Approached In Production Based On The Internet Of Things Paradigm," Ieee Int. Conf. Ind. Eng. Eng. Manag., Vol. 2015-Janua, Pp. 697701, 2014.

[2] M. Crnjac And N. Banduka, "From Concept To The Introduction Of Industry 4 . 0," Vol. 8, No. 1, Pp. 21-30, 2017. 
[3] S. S. Brodjonegoro, "Kecakapan Era 4.0," Vol. 0, Pp. 1-2, 2018.

[4] E. Di Gropello, A. Kruse, And P. Tandon, Skills For The Labor Market In Indonesia. 2011.

[5] D. Jendral, K. Riset, And P. Tinggi, "Kerangka Kualifikasi Nasional Indonesia Dokumen 001," Pp. 1-9, 2015.

[6] Republik Indonesia, "Standard National Pendidikan Tinggi," Peratur. Menteri Pendidik. Dan Kebud. Republik Indones., p. 31, 2014.

[7] P. H. M. Gurgel, L. H. C. Branco, E. F. Barbosa, And K. R. L. J. C. Branco, "Development Of a Practical Computer Network Course Through Netkit Virtualization Tool," Procedia Comput. Sci., Vol. 18, Pp. 2583-2586, 2013.

[8] M. F. Aburdene, X. Meng, And G. L. Mokodean, "Analysis Of Computer Networks Courses In Undergraduate Computer Science, Electrical Engineering And Information Science Programs," 2004.

[9] T. P. K. Dikti, "Tim Pengembang Kurikulum Dikti," Tim Pengembang Kurikulum Dikti, 2012.

[10] R. A. Reaux, R. W. Ehrich, F. Mccreary, K. Rowland, And S. Hood, "Pcs For Families: A Study Of Early Intervention Using Networked Computing In Education," J. Educ. Comput. Res., Vol. 19, No. 4, Pp. 383-410, 1998.

[11] P. M. Papadopoulos, T. D. Lagkas, And S. N. Demetriadis, "How To Improve The Peer Review Method: Free-Selection Vs Assigned-Pair Protocol Evaluated In a Computer Networking Course," Comput. Educ., Vol. 59, No. 2, Pp. 182-195, 2012.

[12] D. Duvivier, G. Quesnel, And E. Ramat, "Virtual Laboratory Environment Conclusion Perspectives," Vol. 53, No. 2, Pp. 216-222, 2010.

[13] M. Montero And D. R. Manzano, "Design And Deployment Of Hands-On Network Lab Experiments For Computer Science Engineers *,"Vol. 33, No. 2, Pp. 855-864, 2017.

[14] P. Segeč, M. Kubina, And P. Palúch, "Viro - The Online Tool For The Networking Education," Procedia - Soc. Behav. Sci., Vol. 174, Pp. 37883796, 2015.

[15] N. M. M. Noor, N. Yayao, And S. Sulaiman, "Effectiveness Of Using Cisco Packet Tracer As a Learning Tool: A Case Study Of Routing Protocol," Int. J. Inf. Educ. Technol., Vol. 8, No. 1, Pp. 11-16, 2018.

[16] M. Gusev, S. Ristov, And A. Donevski, "Integrating Practical Cisco Ccna Courses In The Computer Networks' Curriculum," Ieee Glob. Eng. Educ. Conf. Educon, No. April, Pp. 499506, 2014.

[17] L. Evans, "The Effectiveness Of Using Virtual Laboratories To Teach Computer Networking Skills In Zambia," J. Chem. Inf. Model., Vol. 53, No. 9, Pp. 1689-1699, 2013.

[18] P. Gil, F. A. Candelas, And C. A. Jara, "Computer Networks E-Learning Based On
Interactive Simulations And Scorm," Int. J. Online Eng., Vol. 7, No. 2, Pp. 15-23, 2011.

[19] E. Z. Red, "Students' Performance And Satisfaction With The Cisco Academy Networking Program (Computer Networking 1): Basis For a Proposed Pedagogical Action In Blended Learning," Int. J. Multidiscip. Res., Vol. 2, No. September, Pp. 183-198, 2012.

[20] M. Beheshti And A. Pakfar, "Using Intelligent Educational Technology In Computer Network," Procedia - Soc. Behav. Sci., Vol. 116, Pp. 29942997, 2014.

[21] H. a Lahoud And J. P. Krichen, "Networking Labs In The Online Environment: Indicators For Success," J. Technol. Stud., Vol. 36, No. 2, Pp. 31-40, 2010.

[22] E. G. Bradley And B. Kendall, "A Review Of Computer Simulations In Teacher Education," $J$. Educ. Technol. Syst., Vol. 43, No. 1, Pp. 3-12, 2014.

[23] T. M. Sanguino, "Wifisim: An Educational Tool For The Study And Design Of Wireless Networks," Ieee Trans. Educ., Vol. 56, No. 2, Pp. 149-155, 2013.

[24] N. Spyropoulou, G. Demopoulou, C. Pierrakeas, I. Koutsonikos, And A. Kameas, "Developing a Computer Programming Mooc," Procedia Comput. Sci., Vol. 65, No. Iccmit, Pp. 182-191, 2015.

[25] H. Wang, "Development And Implementation Of Engineering Materials And Thermal Processing Network Course Based On Autonomous Learning," Procedia Eng., Vol. 15, Pp. 127-131, 2011.

[26] H. Igor, J. Bohuslava, J. Martin, And N. Martin, "Application Of Neural Networks In Computer Security," Procedia Eng., Vol. 69, Pp. 12091215, 2014.

[27] F. Ö. K. Bakioğlu, E. Kartal, Z. Özen, Ç. S. Erol, And S. Gülseçen, "Aspects Of Students About Information Technology Courses In Social Science," Procedia - Soc. Behav. Sci., Vol. 176, Pp. 148-154, 2015.

[28] N. Jovanovic, R. Popovic, And Z. Jovanovic, "Wnetsim : a Web-Based Computer."

[29] L. Xu, D. Huang, And W. Tsai, "V-Lab: a CloudBased Virtual Laboratory Platform For HandsOn Networking Courses," Proc. 2012 Acm Conf. Innov. Technol. Comput. Sci. Educ., Pp. 256-261, 2012.

[30] G. Jones, "Academic Use Of Commercial Network Simulation Tools," Int. J. Electr. Eng. Educ., Vol. 37, No. 2, Pp. 136-145, 2000.

[31] W. R. Franta, "A Generalized Simulator For Computer Networks," Pp. 123-132.

[32] H. Ueda And M. Nakamura, "Data Analysis For Evaluation On Course Design And Improvement Of 'Cyberethics' Moodle Online Courses," Procedia Comput. Sci., Vol. 112, Pp. 2345-2353, 2017. 
[33] C. Etus, "An Overview Of Network Simulation Tools In Teaching Computer Network," Vol. 2, No. 11, Pp. 479-485, 2015.

[34] N. Jalinus, R. A. Nabawi, And A. Mardin, "The Seven Steps Of Project Based Learning Model To Enhance Productive Competences Of Vocational Students," Vol. 102, No. Ictvt, Pp. 251-256, 2017.

[35] W. Y. Hwang, C. Kongcharoen, And G. Ghinea, "To Enhance Collaborative Learning And Practice Network Knowledge With a Virtualization Laboratory And Online Synchronous Discussion," Int. Rev. Res. Open Distance Learn., Vol. 15, No. 4, Pp. 113-137, 2014.

[36] B. Cameron, "The Effectiveness Of Simulation In a Hybrid And Online Networking Course," Techtrends, Vol. 47, No. 5, Pp. 18-21, 2003.

[37] D. P. Mahesi Agni Zaus, Rizky Ema Wulansari, Syaiful Islami, "Perancangan Media Pembelajaran Listrik Statis Dan Dinamis Berbasis Android," Vol. 1, No. 1, Pp. 1-7, 2018.

[38] N. S. Foundation Et Al., "In," No. 14.

[39] Z. Ran, "Exploration On The Key Issues Of Practical Teaching Reform Of Computer Network," Energy Procedia, Vol. 17, Pp. 19141919, 2012.

[40] D. Pernanda, M. A. Zaus, R. E. Wulansari, And S. Islami, "Effectiveness Of Instructional Media Based On Interactive $\mathrm{Cd}$ Learning On Basic Network At Vocational High School : Improving Student Cognitive Ability Effectiveness Of Instructional Media Based On Interactive $\mathrm{Cd}$ Learning On Basic Network At Vocational Hig," Int. Conf. Educ. Soc. Sci. Technol., No. February, 2018.

[41] A. Yulastri, H. Hidayat, Ganefri, S. Islami, And F. Edya, "Developing An Entrepreneurship Module By Using Product-Based Learning Approach In Vocational Education," Int. J. Environ. Sci. Educ., Vol. 12, No. 5, Pp. 1097-
1109, 2017.

[42] H. Effendi, "Peningkatan Hasil Belajar Siswa Menggunakan Software Ekts Pada Mata Pelajaran Pengendali Elektromagnetik.Pdf." .

[43] D. Fatmadilla, Usmeldi, And Krismadinata, "Penerapan Strategi Training Within Industry Dalam Pembelajaran Mengoperasikan Sistem Pengendali Elektromagnetik.Pdf.” 2017.

[44] M. L. Hamzah And A. A. Purwati, "Sistem Manajemen Inventori Komputer Menggunakan Near Field Communication Berbasis Android (Studi Kasus Di Stie Pelita Indonesia Pekanbaru) Computer," J. Econ. Bus. Account., Vol. 1, No. 1, Pp. 95-104, 2017.

\section{Biodata Penulis}

Mahesi Agni Zaus, lahir di Bukittinggi, 26 Juli 1992. Sarjana Pendidikan Teknik Informatika dari Universitas Negeri Padang, lulus 2014. Tahun 2016 memperoleh gelar Magister Pendidikan Tenik pada Jurusan Pendidikan Teknologi dan Kejuruan Universitas Negeri Padang

Krismadinata, lahir di Padang, 11 September 1977. Menyelesaiakan studi S1 di Universitas Andalas, S2 di Institut Teknologi Bandung, dan S3 di Universitas Malaya. Dosen di Jurusan Teknik Elektro Fakultas Teknik Universitas Negeri Padang sejak tahun 2000-sekarang 